\title{
Efficacy of Hawthorn Fruit Extract on Blood Pressure and Quality of Sleep in Patients with Hypertension along with Sleep Disorders: A Randomized Double-Blind Controlled Trial
}

\author{
Masumeh Abbasi', Sepehr Gohari², Hassan Ahangar ${ }^{3 *}$, Mohsen Bahramii, Mohammad Kamalinejad ${ }^{5}$, \\ Tara Reshadmanesh², Seyede Shadi Nazari ${ }^{6}$
}

'Department of Persian and Traditional Medicine, School of Medicine, Zanjan University of Medical Sciences, Zanjan, Iran.
2Student Research Center, School of Medicine, Zanjan University of Medical Sciences, Zanjan, Iran.
'Department of Cardiology, Mousavi Hospital, School of Medicine, Zanjan University of Medical Sciences, Zanjan, Iran.
${ }^{4}$ Department of Persian and Traditional Medicine, Academic Center for Education, Culture and Research Center, Tehran, Iran.
${ }^{5}$ Department of Pharmacognosy, Faculty of Pharmacy, Shahid Beheshti University of Medical Sciences, Tehran, Iran.
${ }^{6}$ Department of Biostatistics, School of medicine, Zanjan university of Medical Sciences, Zanjan, Iran.
*Correspondence to: Hassan Ahangar (E-mail: masumehabbasi45@yahoo.com )
(Submitted: 25 March 2021 - Revised version received:08 April 2021 - Accepted:21 May 2021 - Published online: 26 August 2021)

\begin{abstract}
Objectives This study aimed to investigate the effect of Crataegus monogyna (C. monogyna) on controlling the blood pressure in patients with hypertension along with sleep disorder.

Methods This was a parallel double-blind, placebo-controlled trial study from May, 2018 to December, 2019. Total of 60 patients with hypertension and sleep disorder were randomly assigned to C. monogyna and placebo groups. The groups received C. monogyna and placebo capsules twice-daily for 8 weeks. The primary outcomes were the changes of systolic and diastolic blood pressure and Pittsburgh questionnaire's scores from baseline measurements. The secondary outcomes were changes in serum biochemical markers from baseline. Results Before treatment, there was no significant difference between study groups in terms of demographic data and outcomes $(P>0.05)$ except body mass index $(P=0.02)$. After treatments the intervention group had a significant improvement in systolic and diastolic blood pressure compared to placebo ( $(118.14 \pm 6.76$ vs $129.76 \pm 8.28,95 \% \mathrm{Cl}: 7.54-15.69, P<0.001$ and $77.14 \pm 5.32$ vs $83.57 \pm 6.73,95 \%$ Cl: 3.17-9.68, $P<0.001$, respectively) analysis revealed no significant difference observed between study groups in terms of baseline characteristics, and pre- and posttreatment laboratory tests. Also, none of the groups had superiority in terms of Pittsburgh questionnaire's scores $(P=0.44)$; however, the intragroup analysis revealed a significant improvements in the intervention group $(P=0.001)$.

Conclusion C. monogyna fruit extract as a supplementary medication has beneficial effects on controlling blood pressure and quality of sleep in patients with hypertension along with sleep disorders.

Keywords Hypertension, sleep disorder, quality of sleep, Crataegus monogyna, randomized controlled trial
\end{abstract}

\section{Introduction}

Hypertension (HTN) is a major and modifiable risk factor for the development of cardiovascular diseases in population all around the world. ${ }^{1}$ According to the WHO, hypertension causes a serious health problem in most developing countries and contributes to a significant burden on health systems. ${ }^{2}$ Several factors associated with lifestyle and environment, including obesity, urbanization, less exercise, and sedentary life, have attributed to the increased rate of hypertension and other vascular diseases. ${ }^{3,4}$ Although the incidence of hypertension increases rapidly, only one-third of the cases have their disease under control, and drug compliance is alarmingly low. ${ }^{5}$ Therefore, with due attention to the adverse events and compromised efficiency of industrial drugs and medications, recently, traditional remedies have gained crucial favor as an alternative for the treatment of hypertension. ${ }^{6}$ According to the literature of traditional medicine, hypertension has not been considered as a single and solitary disease and has suggested being arisen as a complication of cardiovascular and hemodynamic abnormalities. ${ }^{7}$ On this basis, several Iranian ancient wises, such as Avicenna, have suggested medicinal plants to play a significant role in the avoidance and treatment of hypertension.
On the other hand, it has been established that sleep disorders also aggravate hypertension severity and interfere with the control of the illness, by provoking higher BP. ${ }^{8-11}$ The association of sleep disorders with increased and less-controlled hypertension has been confirmed through several studies. ${ }^{12}$ Whereas, middle-aged individuals are at lower risk for hypertension by curing their sleep disorders. ${ }^{13}$ Crataegus monogyna (C. monogyna), also known as "Hawthorn" is one of the herbal plants which has been discussed in ancient literature. The fruit of the plant presents in reddish color with an oval shape. In traditional literature, it has been called in several names, such as "Zalzalak" (kind of wide plum) and "Kiyalak" Concerning its temperament, C. monogyna is known to have a cold temper, and according to the ancient Iranian wises, it has several beneficiary effects on diarrhea, gastrointestinal reflux disorder, palpitation and cardiovascular disorders. The consumable part of these plants includes flowers, leaves, and fruits, which are used more often compared to their bushes. ${ }^{7,14}$ Many of the beneficial effects of C. monogyna fruit are attributed to its flavonoid and phenolic components such as hyperoside, chlorogenic acid, and isoquercetin. ${ }^{15}$ On this basis, in the current randomized clinical trial, we primarily aimed to investigate 
the clinical effect of C. monogyna fruit extract on controlling the blood pressure of patients suffering from hypertension along with sleep disorders.

\section{Materials and Methods}

\section{Study Design}

This was a phase III, parallel double-blind, placebo-controlled randomized trial study to investigate the effects of $C$. monogyna capsules (500 $\mathrm{mg} /$ twice daily) versus placebo on the quality of sleep and blood pressure in patients with concomitant HTN and sleeping disorder. The study protocol was approved by ethics committee of the Zanjan University of Medical Sciences (A-12-594-22), and was subsequently registered in Iranian Registry for Clinical Trials (IRCT, ID: IRCT20180225038859N1). All the patients provided written informed consent.

\section{Study Patients and Setting}

The eligible study population was selected from patients in cardiology special clinic in Zanjan, Iran. The recruitment started from May, 2018 to December, 2019. During this period, 81 patients assessed for eligibility. Of these 21 patients were excluded and 60 patients enrolled in the study.

From May, 2018 to December, 2019 till end of 2019, a double-blinded randomized controlled trial was carried in cardiology clinic of the Zanjan University of Medical sciences, Zanjan, Iran. All patients with HTN diagnosis were screened to participate in the study. All patients aged 35-60 years old, who were suffering from first stage of HTN (systolic blood pressure (BP): 140-159 $\mathrm{mmHg}$, or diastolic BP: 90-99 $\mathrm{mmHg}$ ) at least for one year, were enrolled in the study. Patients with severe HTN who required multiple-drug treatment, secondary HTN, end-organ complications (in the last six months), cardiac arrhythmia, valvular heart diseases, malignancy, psychiatric conditions, hepatic dysfunction, and pregnancy, were excluded, as well as the individuals with increased BP up to $180 / 110 \mathrm{mmHg}$.

\section{Study Procedure}

\section{Randomization and Follow up}

Recruited patients were stratified (according to Age and Gender) and assigned into 2 groups of C. monogyna and placebo in a 1:1 ratio. The randomization sequence was created by Winpepi software (Version 11.6). At the recruitment date, patients' demographic data including age, height and weight, history of underlying disease, concurrent medications (including herbal and chemical), and possible allergies were recorded. The Drugs were prescribed two months (500 mg capsul/Twice daily). During study period, patients were regularly visited every two weeks at the clinic to record vital signs and evaluate the study progress. Patients were advised to continue clinic visits even if they decided to quit the study.

\section{Outcomes}

The primary outcomes were 1) Changes in systolic blood pressure (SBP) and diastolic blood pressure (DBP) after 8 weeks of treatment. 2) Changes in Quality of sleep after 8 weeks of treatment using Pittsburgh questionnaire. ${ }^{16}$
The secondary outcomes comprised of changes in laboratory biomarkers after 9 weeks from the baseline including: 1) Blood urea nitrogen (BUN), 2) Creatinine (Cr), 3) Aspartate aminotransferase (AST), 4) Alanine transaminase (ALT), 5) Triglyceride (TG), 6) Total Cholesterol, 7) High density lipoprotein cholesterol (HDL-C), 8) Low density lipoprotein cholesterol (LDL-C). To assess the secondary outcomes, a biobank was established in which patients' serum was stored in an ultra-low temperature freezer. Based on the regulations of the local data protection agency, after the measurements, all the remaining samples will be anonymized and the biobank will be discontinued.

\section{Blinding}

C. monogyna and placebo capsules with same shape, color, and package and different code numbers were used for treatment groups $\mathrm{A}$ and $\mathrm{B}$. At the time of recruitment, a unique code number was assigned to each patient and was used till the end of the study. Patients, investigators, outcome assessors and healthcare providers were blinded to the treatment groups. The unblended treatment list was held by the Zanjan University Medical Documentation Council.

\section{Drug Preparation}

\section{Preparation of Fruit Extract}

To prepare a C. monogyna fruit concentrate capsules, the plant washed completely, to eliminate contaminants. Then, $100 \mathrm{gr}$ of fruit was poured with $1 \mathrm{~L}$ water in a beaker and boiled over the flame. After boiling for three hours, the beaker was cooled down at the room temperature, and the solution was filtrated. The rotatory evaporator was used to purify and condense the solution and extract the concentrate. Usually, the dry weight of the extract is $10 \%$ of the C. monogyna extract; consequently, we added the Exetian (a corn starch), which is used as a neutral ingredient in pharmaceutical industry. Finally, $500 \mathrm{mg}$ capsules of C. monogyna concentrate were prepared, while $250 \mathrm{mg}$ of the powder, containing active compound, was poured into the capsule, as well as the $250 \mathrm{mg}$ of the supplementary material, described above. Accordingly, in order to provide similar medications with neutral effect in placebo group, $500 \mathrm{mg}$ capsules with corn starch were prepared. Finally, capsules were prepared in specific bottles containing 60 capsules. All the mentioned process (drug preparation) was done at Shahid Beheshti University of Medical Sciences.

\section{Total Phenol Content (TPC)}

To measure TPC, $1 \mathrm{ml}$ of gallic acid with different concentrations $(20,40,60,80$ and $100 \mu \mathrm{g} / \mathrm{mL})$ was mixed with FolinCiocalteu reagent ( $5 \mathrm{~mL}, 1: 10$ diluted with distilled water) for $10 \mathrm{~min}$ and aqueous $\mathrm{Na}_{2} \mathrm{CO}_{3}(4 \mathrm{~mL}, 7.5 \mathrm{mg} / \mathrm{mL})$ was then added. The mixture was incubated at dark in room temperature for $30 \mathrm{~min}$. Finally, the absorption rate at $765 \mathrm{~nm}$ was determined using spectrophotometer. After preparing the gallic acid calibration curve with the mentioned concentrations, the measurement was repeated with the extracted solution $(1 \mathrm{~mL}, 30 \mathrm{mg} / \mathrm{mL})$ instead of gallic acid and total phenolic content was determined using the gallic acid standard curve.

\section{Total Flavonoid Content (TFC)}

To measure the TFC, $2.5 \mathrm{~mL}$ of rutin solution with different concentrations $(20,40,60,80$ and $100 \mu \mathrm{g} / \mathrm{mL})$ mixed with 
aluminum chloride $(2.5 \mathrm{~mL}, 20 \mathrm{mg} / \mathrm{mL})$ solution in ethanol $80 \%$ for $40 \mathrm{~min}$. Finally, the absorption rate at $415 \mathrm{~nm}$ was determined using spectrophotometer. After preparing the rutin calibration curve with the mentioned concentrations, the measurement was repeated with the extracted solution $(2.5 \mathrm{~mL}, 30 \mathrm{mg} / \mathrm{mL})$ instead of rutin and total flavenoid content was determined using the rutin standard curve.

\section{Statistical Considerations}

\section{Sample Size}

The sample size was estimated for the Blood Pressure assessments based on the changes in Mean arterial pressure (MAP). According to previous study, ${ }^{17}$ with a study power of $80 \%$, an alpha level of 0.05 , a beta level of $0.20, S_{1}=6.8, X_{1}=82.6$ and $S_{2}=9.7, X_{2}=91.0$, using the formula below the sample size was calculated to be 24 patients each arm. Considering dropout during the study, the sample size was rounded up to 30 participants in each arm.

$$
n=\frac{\left(s_{1}^{2}+s_{2}^{2}\right)^{2}\left(z_{1-\frac{\alpha}{2}}+z_{1-\beta}\right)^{2}}{\left(\bar{x}_{1}-\bar{x}_{2}\right)^{2}}
$$

\section{Statistical Analysis}

The student $\mathrm{T}$ test used for comparing quantitative variables between groups and the Chi-square Test for comparing two qualitative variables in each time, and between different times.
To determine if there are differences between two groups on a continuous or ordinal dependent variable, the Mann-Whitney $\mathrm{U}$ test was used. The level of significance was set at 0.05 , and all results were expressed by frequency (percent) for qualitative variables and Mean \pm SE for quantitative variables. The pairedsample $\mathrm{T}$ test is used to determine if there was a statistically significant intragroup difference before and after the treatment administration. All analyses were done in IBM SPSS statistics software V.25 environment.

\section{Results}

\section{Drug Analysis Results}

The total phenolic and flavonoid contents were $1.42 \mathrm{mg} /$ capsule and $0.43 \mathrm{mg} /$ capsule, respectively.

\section{Demographic Status and Basal Characteristics}

During recruitment phase, 60 patients had enrolled. Four patients were excluded due to severe increase of the BP, and premature discontinuation (Figure 1).

Data from 56 patients was underwent statistical analysis. Among them 23 (41.1\%) patients were male and 33 (58.9\%) were female (Mean \pm SD of age was $49.1 \pm 5.1$ years). In terms of demographic and baseline characteristics, there was no significant difference based on age and gender between the two arms. Body mass index (BMI); however, was significantly higher in $C$. monogyna group $(P=0.02)$ (Table 1$)$.

\section{CONSORT 2010 Flow Diagram}

\section{Enrollment}

Assessed for eligibility $(n=81)$

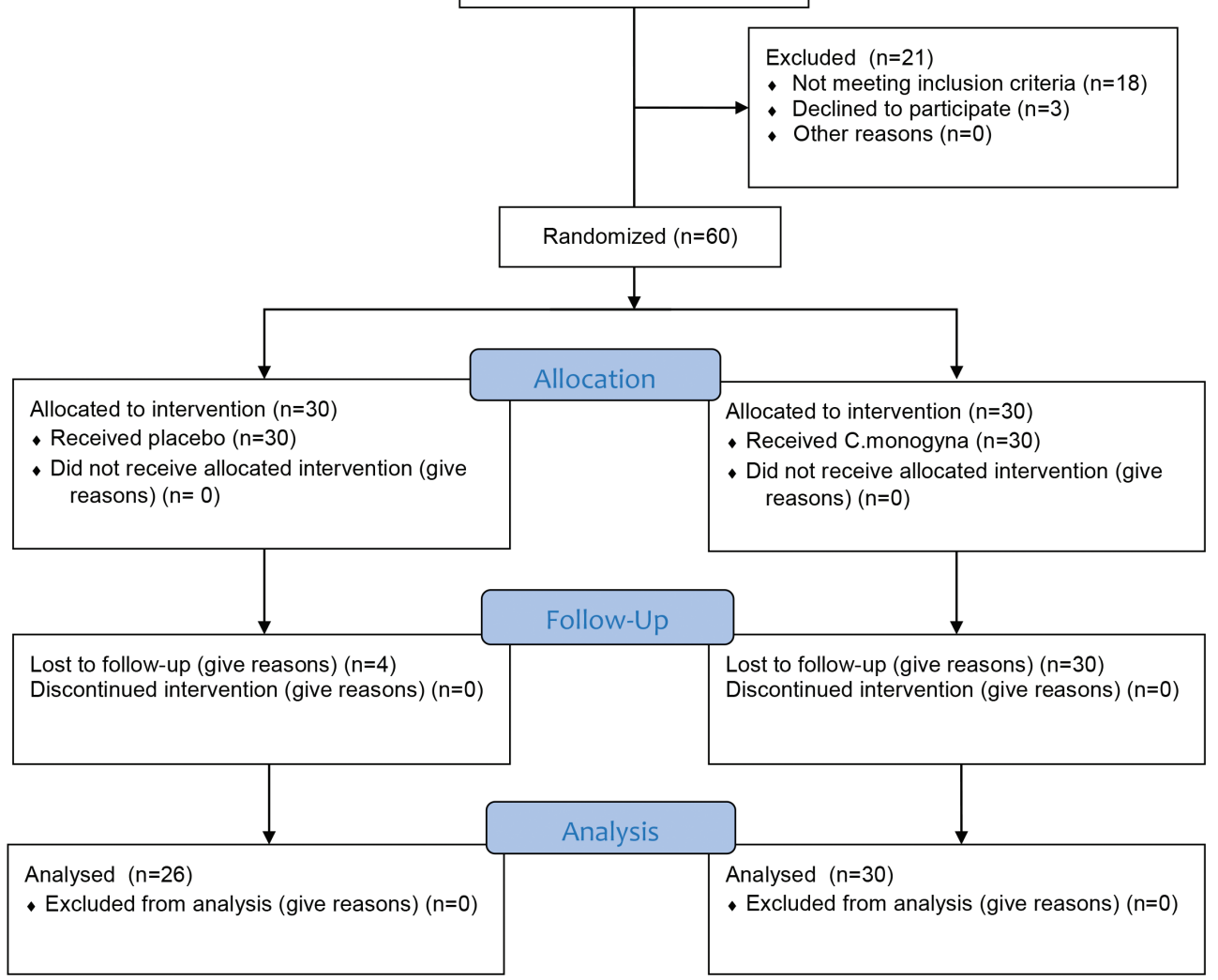

Fig. 1 CONSORT 2010 flow diagram of the study. 


\section{Blood Pressure Assessments}

At baseline, the results of the study showed no significant difference in terms of SBP and DBP between two arms but after 8 weeks of treatment, the SBP and DBP were significantly lower in C. monogyna group (118.14 \pm 6.76 vs $129.76 \pm 8.28$, 95\% CI: 7.54-15.69, $P<0.001$ and $77.14 \pm 5.32$ vs $83.57 \pm 6.73$, 95\% CI: 3.17-9.68, $P<0.001$ ), respectively (Table 2).

\section{Quality of Sleep}

In intragroup analysis, the Pittsburgh questionnaire scores showed a significant decrease of sleep disorders severity in C. monogyna group median (mode) (6(6) vs 4(3), $P=0.001$ ). Interestingly, none of the study arms had superiority after treatment considering the Pittsburgh questionnaire results (4(3) vs 4(4), 95\% CI: -1.49-1.17). However, a satistically significant difference was seen between the two arms at baseline scores (6(6) vs 5(3), 95\% CI: $-3.52-0.21, P=0.03$ ).

\begin{tabular}{|c|c|c|c|c|}
\hline \multirow[b]{2}{*}{ Variables } & & \multicolumn{2}{|c|}{ Mean \pm SD or $n(\%)$} & \multirow[b]{2}{*}{$P$-value } \\
\hline & & $\begin{array}{l}\text { C. monogyna } \\
(N=30)\end{array}$ & $\begin{array}{l}\text { Placebo } \\
(N=26)\end{array}$ & \\
\hline Age & & $49.7 \pm 5.1$ & $48.1 \pm 5.1$ & 0.24 \\
\hline \multirow[t]{2}{*}{ Gender } & Male & $18(50 \%)$ & $18(50 \%)$ & 0.604 \\
\hline & Female & $12(50 \%)$ & $12(50 \%)$ & \\
\hline BMI & & $30.65 \pm 5.7$ & $28 \pm 2.7$ & 0.02 \\
\hline \multirow[t]{7}{*}{ Temperament } & Dry warm & $3(10 \%)$ & $1(3.8 \%)$ & 0.82 \\
\hline & Wet warm & $8(26.6 \%)$ & $5(19.3 \%)$ & \\
\hline & $\begin{array}{l}\text { Tempered } \\
\text { warm }\end{array}$ & $5(16.7 \%)$ & $6(23.1 \%)$ & \\
\hline & Dry cold & $4(13.3 \%)$ & $3(11.5 \%)$ & \\
\hline & Wet col & $5(16.7 \%)$ & $3(11.5 \%)$ & \\
\hline & Tempered cold & $3(10 \%)$ & $5(19.3 \%)$ & \\
\hline & Tempered & $2(6.7 \%)$ & $3(11.5 \%)$ & \\
\hline
\end{tabular}

C. monogyna, Crataegus monogyna; BMI, Body mass index; SD, Standard deviation.

\section{Laboratory Measurements}

In assessment of laboratory variables as secondary outcomes, results of the study showed no significant changes in inter/ intra group analysis at baseline and 1 week after period of treatment between 2 study arms $(P>0.05)$.

\section{Discussion}

Since years, herbal medicine has played a significant role in different aspects of human-being life, whereas it has been suggested to increase the quality of life, improves the signs and symptoms of the diseases, particularly hypertension-related symptoms. ${ }^{18}$ Clinical trials have reported that bioactive compounds to have a protective effect against agents derived from oxidative stress as a risk factor for cardiovascular diseases, which can be found in fruits and vegetables that are vitamins and polyphenols enriched. ${ }^{19,20}$

In the present randomized controlled trial, we primarily aimed to investigate the clinical effects of $C$. monogyna fruit extract on controlling HTN along with sleep disorders. No significant difference observed between study arms in terms of laboratory tests, and none of the groups showed changes in test values after the study period. Our results revealed significant improvements in SBP and DBP after treatment with C. monogyna. In addition, results of the Pittsburgh sleep quality questionnaire showed significant improvement in patients who were treated with C. monogyna compared to pretreatment evaluations.

In a recent study by Haydari et al., the results of an animal experimental indicated that the administration of hydroalcoholic extract of Crataegus azarolus subspecies aronia diminished the HTN development, which was applied by clips placement on renal arteries..$^{21}$ The authors hypothesized that increased NO release and reduction of the oxidative stress through the herbal extract might have played a role in preventing HTN development. Further studies confirmed the antioxidative effects of the C. monogyna, since its acidified methanol or ethanol extracts served as a potential antioxidant and neuroprotective agent. ${ }^{22}$

Sharifi et al. evaluated the angiotensin-converting enzyme (ACE) inhibitory effects in six medicinal plants, known as a potential antihypertensive in Iranian traditional medicine. ${ }^{23}$

\begin{tabular}{|c|c|c|c|c|c|c|}
\hline \multirow[t]{2}{*}{ Variables } & & \multirow{2}{*}{$\begin{array}{c}\text { C. monogyna }(N=30) \\
\text { Mean } \pm \text { SD }\end{array}$} & \multirow{2}{*}{$\begin{array}{c}\text { Placebo }(N=26) \\
\text { Mean } \pm \text { SD }\end{array}$} & \multirow{2}{*}{ Student-t: P } & \multicolumn{2}{|c|}{$95 \% \mathrm{Cl}$} \\
\hline & & & & & Lower & Upper \\
\hline \multirow[t]{3}{*}{ Diastolic BP } & Before & $90.71 \pm 7.39$ & $89.76 \pm 4.32$ & 0.59 & -4.51 & 2.61 \\
\hline & After & $77.14 \pm 5.32$ & $83.57 \pm 6.73$ & $<0.0001$ & 3.17 & 9.68 \\
\hline & Paired:P & $<0.0001$ & 0.001 & & & \\
\hline \multirow[t]{3}{*}{ Systolic BP } & Before & $133.43 \pm 6.50$ & $131.43 \pm 6.73$ & 0.27 & -5.65 & 1.64 \\
\hline & After & $118.14 \pm 6.76$ & $129.76 \pm 8.28$ & $<0.0001$ & 7.54 & 15.69 \\
\hline & Paired:P & $<0.0001$ & 0.47 & & & \\
\hline \multirow[t]{3}{*}{ Pittsburgh score } & Before & $6(3-18)$ & $5(2-8)$ & 0.03 & -3.52 & -0.21 \\
\hline & After & $4(2-13)$ & $4(2-8)$ & 0.44 & -1.49 & 1.17 \\
\hline & Paired:P & 0.001 & 0.61 & & & \\
\hline
\end{tabular}

C. monogyna, Crataegus monogyna; BP, Blood pressure; Cl, Confidence interval; SD, Standard deviation. 


\begin{tabular}{|c|c|c|c|c|c|c|}
\hline \multirow[t]{2}{*}{ Variables } & & \multirow{2}{*}{$\begin{array}{c}\text { C. monogyna }(N=30) \\
\text { Mean } \pm S D\end{array}$} & \multirow{2}{*}{$\begin{array}{c}\text { Placebo }(N=26) \\
\text { Mean } \pm \text { SD }\end{array}$} & \multirow{2}{*}{ Student-t: P } & \multicolumn{2}{|c|}{$95 \% \mathrm{Cl}$} \\
\hline & & & & & Lower & Upper \\
\hline \multirow[t]{3}{*}{ BUN } & Before & $13.86 \pm 5.32$ & $14.16 \pm 4.02$ & 0.82 & -2.51 & 3.11 \\
\hline & After & $15.90 \pm 5.74$ & $14.61 \pm 5.42$ & 0.41 & -4.47 & 1.89 \\
\hline & Paired:p & 0.15 & 0.77 & & & \\
\hline \multirow[t]{3}{*}{$\mathrm{Cr}$} & Before & $1 \pm 0.15$ & $1.06 \pm 0.16$ & 0.18 & -0.03 & 0.15 \\
\hline & After & $0.93 \pm 0.15$ & $1 \pm 0.18$ & 0.16 & -0.02 & 0.16 \\
\hline & Paired:p & 0.08 & 0.27 & & & \\
\hline \multirow[t]{3}{*}{ AST } & Before & $21.56 \pm 9.89$ & $24.48 \pm 10.50$ & 0.30 & -8.39 & 7.53 \\
\hline & After & $23.81 \pm 8.32$ & $32.74 \pm 11.36$ & 0.13 & -7.63 & 21.69 \\
\hline & Paired:p & 0.34 & 0.28 & & & \\
\hline \multirow[t]{3}{*}{ ALT } & Before & $25.32 \pm 15.32$ & $24.95 \pm 12.40$ & 0.91 & -2.72 & 8.56 \\
\hline & After & $25.20 \pm 15.20$ & $32.21 \pm 17.07$ & 0.34 & -2.79 & 20.64 \\
\hline & Paired:p & 0.97 & 0.13 & & & \\
\hline \multirow[t]{3}{*}{ Triglyceride } & Before & $166.49 \pm 65.21$ & $164.33 \pm 76.70$ & 0.91 & -40.72 & 36.41 \\
\hline & After & $168.24 \pm 69.42$ & $161.24 \pm 54.78$ & 0.69 & -42.78 & 28.79 \\
\hline & Paired:p & 0.92 & 0.88 & & & \\
\hline \multirow[t]{3}{*}{ Cholesterol } & Before & $181.74 \pm 42.21$ & $188.86 \pm 32.47$ & 0.51 & -14.41 & 28.64 \\
\hline & After & $184.12 \pm 43.45$ & $190.81 \pm 38.61$ & 0.56 & -16.52 & 29.9 \\
\hline & Paired:p & 0.83 & 0.86 & & & \\
\hline \multirow[t]{3}{*}{$\mathrm{HDL}-\mathrm{C}$} & Before & $44.17 \pm 9.06$ & $44.38 \pm 7.30$ & 0.92 & -4.47 & 4.89 \\
\hline & After & $41.50 \pm 9.27$ & $42.25 \pm 10.10$ & 0.78 & -4.67 & 6.17 \\
\hline & Paired:p & 0.26 & 0.44 & & & \\
\hline \multirow[t]{3}{*}{ LDL-C } & Before & $97.96 \pm 30.32$ & $116.86 \pm 32.45$ & 0.07 & -1.79 & 39.58 \\
\hline & After & $111.41 \pm 36.10$ & $121.05 \pm 33.09$ & 0.35 & -11.13 & 30.41 \\
\hline & Paired:p & 0.12 & 0.71 & & & \\
\hline
\end{tabular}

C.monogyna, Crataegus monogyna; BUN, Blood urea nitrogen; AST, Aspartate transaminase; ALT, Alanin transaminase; HDL, High density lipoprotein cholesterol; LDL, Low density lipoprotein cholestero; SD, Standard deviation; Cl, Confidence interval.

Although the outcomes revealed high ACE inhibition and antioxidant activity for several other herbal medicines such as Q. infectoria and O. acanthium, serious adverse events might be occurred due to their toxic ingredients. However, C. monogyna had not only significant superiority in terms of ACE inhibition activity but also showed no toxic effects or adverse effects. Similarly, our results showed that C.monogyna prescription had significantly improved the systolic and diastolic $\mathrm{BP}$ compared to patients who received a placebo. Our findings were in accordance with the study by Wang et al., which demonstrated the effects of $C$. monogyna in decreasing systolic and diastolic BP, as well as the heart rate. ${ }^{24}$ Also, our results confirm the report by Hernandez et al., which introduced a significant vasorelaxant activity for C. monogyna. ${ }^{25}$

Besides, the sleep quality of the patients who received C. monogyna had significantly enhanced. Considering the fact that the correlation between uncontrolled HTN and low sleep quality is well-established, it can be hypothesized that C. monogyna benefits several advantages in controlling the HTN, including ACE inhibitory effect and improving the sleep quality. In addition, during the two-month administration of the C. monogyna extracts, no adverse effect was reported by patients, which emphasizes the safety of the herb, which was in coincidence with the study by Kumaraswamy et al., which reported no toxic activity by $2000 \mathrm{mg}$ daily consumption of C. monogyna. ${ }^{26}$

Although our findings contribute significantly to prove the efficiency and safety of the C. monogyna in treatment of the patients with HTN, the herbal medications are far from replacing the routine, conventional therapies, and they can only serve as a supplement to routine prescriptions. In addition, further studies are needed to make more evidence available on traditional claims over the effectivity of the herbs and medicinal plants, through well-designed and structured clinical trials and systematic reviews on modern and traditional literature.

\section{Conclusion}

C. monogyna fruit extract as a supplementary medication in patients with HTN resulted in the better controlling of the systolic and diastolic blood pressures in comparison to the placebo. In addition, the sleep quality of the patients, who underwent treatment with C. monogyna was significantly improved after the treatment course. However, further studies with possibly longer administration and follow-up period are 
required to illuminate the benefits of the medical plant mentioned above.

\section{Data Availability}

The raw data supporting the findings of this study are available from the corresponding author on request.

\section{Conflicts of Interest}

The authors contributed in this study have no conflict of interest to disclose.

\section{Funding}

This study was not founded by any organization or committee.

\section{Acknowledgments}

We thank Prof. Soghrat Faghihzadeh and Dr. Narjes Khavasi for their valuable consults through statistical analysis and study design. We also thank all of the patients for their participation and good cooperation throughout the study.

\section{References}

1. Stamler J, Stamler R, Neaton JD, Wentworth D, Daviglus ML, Garside D, et al. Low risk-factor profile and long-term cardiovascular and noncardiovascular mortality and life expectancy: findings for 5 large cohorts of young adult and middle-aged men and women. Jama. 1999;282(21):2012-18

2. Forouzanfar MH, Liu P, Roth GA, Ng M, Biryukov S, Marczak L, et al. Global burden of hypertension and systolic blood pressure of at least 110 to 115 mm Hg, 1990-2015. Jama. 2017:317(2):165-82.

3. Dardi F, Palazzini M, Gotti E, Zuffa E, De Lorenzis A, Daniele G, et al. Additional Role of Unmodifiable Risk Factors in Pulmonary Arterial Hypertension Risk Stratification According to Current ESC/ERS Guidelines. Circulation. 2019;140(Suppl_1):A9541-A.

4. Daştan I, Erem A, Çetinkaya V. Urban and rural differences in hypertension risk factors in Turkey. Anatol J cardiol. 2017;18(1):39

5. Pandey $R$, Quan WY, Hong F. Vaccine for hypertension: modulating the renin-angiotensin system. Int J cardiol. 2009;134(2):160-8.

6. Dabaghian FH, Rassouli M, Sadighi J, Ghods R. Adherence to prescribed medications of Iranian traditional medicine in a group of patients with chronic disease. J Res Pharm Pract. 2016;5(1):52.

7. Ibn Sina H. The Canon of medicine. Beirut: Alaalamy Foundation Publications. 2005

8. Calhoun D. Sleep disorders and hypertension risk. J Hum Hypertens. 2017;31(6):371-2.

9. Calhoun DA. Obstructive sleep apnea and hypertension. Curr. Hypertens. Rep. 2010;12(3):189-95.

10. Calhoun DA, Harding SM. Sleep and hypertension. Chest. 2010;138(2):434-43.

11. Fiorentini A, Valente R, Perciaccante A, Tubani L. Sleep's quality disorders in patients with hypertension and type 2 diabetes mellitus. Int J Cardiol. 2007;114(2):E50-E2

12. Seravalle G, Mancia G, Grassi G. Sympathetic nervous system, sleep, and hypertension. Curr. Hypertens. Rep. 2018;20(9):74.

13. Gangwisch JE, Malaspina D, Posner K, Babiss LA, Heymsfield SB, Turner JB, et al. Insomnia and sleep duration as mediators of the relationship between depression and hypertension incidence. Am J Hypertens. 2010;23(1):62-9.

14. MH AK. Makhzan-ol-advieh. Tehran: Sabz arang publication. 2008.

15. Alirezalu A, Ahmadi N, Salehi P, Sonboli A, Alirezalu K, Mousavi Khaneghah A, et al. Physicochemical characterization, antioxidant activity, and phenolic compounds of Hawthorn (Crataegus spp.) fruits species for potential use in food applications. Foods. 2020;9(4):436

16. Buysse DJ, Reynolds CF, MonkTH, Berman SR, Kupfer DJ. The Pittsburgh Sleep Quality Index: a new instrument for psychiatric practice and research. Psychiatry res. 1989;28(2):193-213.

17. Baddeley-White DS, McGowan CL, Howden R, Gordon BD, Kyberd P, Swaine IL. Blood pressure lowering effects of a novel isometric exercise device following a 4-week isometric handgrip intervention. Open Access J Sports Med. 2019;10:89.

18. Ghorbani M. Iranian traditional medicine for treatment of type II diabetes, anxiety and hypertension with introduction of zebrafish model system for their screening. Int J Herb Med. 2014:2(5):13-9.

19. Kris-Etherton PM, Hecker KD, Bonanome A, Coval SM, Binkoski AE, Hilpert $\mathrm{KF}$, et al. Bioactive compounds in foods: their role in the prevention of cardiovascular disease and cancer. Am J Med. 2002;113(9):71-88.

20. Sato K, Dohi Y, Kojima M, Miyagawa K, Takase H, Katada E, et al. Effects of ascorbic acid on ambulatory blood pressure in elderly patients with refractory hypertension. Arzneimittelforschung. 2006;56(07):535-40.

21. Haydari MR, Panjeshahin MR, Mashghoolozekr E, Nekooeian AA. Antihypertensive effects of hydroalcoholic extract of crataegus azarolus subspecies aronia fruit in rats with renovascular hypertension: an experimental mechanistic study. Iran J Med Sci. 2017;42(3):266

22. Renda G, Özel A, Barut B, Korkmaz B, Yayli N. In Vitro Protection by Crataegus microphylla Extracts Against Oxidative Damage and Enzyme Inhibition Effects. Turkish J Pharm. Sci. 2018:15(1).

23. Sharifi N, Souri E, Ziai SA, Amin G, Amanlou M. Discovery of new angiotensin converting enzyme (ACE) inhibitors from medicinal plants to treat hypertension using an in vitro assay. DARU J Pharm Sci. 2013;21(1):74

24. Wang J, Xiong $X$, Yang G, Zhang Y, Liu Y, Zhang Y, et al. Chinese herbal medicine qi ju di huang wan for the treatment of essential hypertension: a systematic review of randomized controlled trials. Evid Based Complement Alternat Med 2013;2013.

25. Hernández-Pérez A, Bah M, Ibarra-Alvarado C, Rivero-Cruz JF, Rojas-Molina A, Rojas-Molina JI, et al. Aortic relaxant activity of Crataegus gracilior Phipps and identification of some of its chemical constituents. Molecules. 2014;19(12):20962-74

26. Shatoor AS. Acute and sub-acute toxicity of Crataegus aronia syn. azarolus (L.) whole plant aqueous extract in wistar rats. Am J Pharmacol Toxicol. 2011;6(2):37-45 